\title{
El arte de volar en Ovidio: el efecto de los preverbios sobre un verbo de manera de moverse
}

\section{ANA LORENA NIETO MANINI}

Universidad Nacional de San Juan / Universidad de Salamanca

alorenanietom@gmail.com / alnietomanini@usal.es

Desde un marco lingüístico funcional y cognitivo, se estudia el efecto de los preverbios añadidos en un Verbo de Manera de Moverse: volare. El corpus se establece desde toda la obra poética de Ovidio a partir del estudio de la diferencia semántica y gramatical de volare en forma simple y compuesta y la alteración de la telicidad y transitivación de las cláusulas.

El latín es una lengua de marco por satélite y por lo tanto la añadidura de preverbios corroborará o no las hipótesis establecidas acerca de sus efectos.

Verbos de Manera de Moverse / Lengua de marco por satélite / Telicidad / Transitivación / Preverbios

THE ART OF FLYING IN OVIDIUS: THE EFFECT OF PREVERBS ON MANNER OF MOVEMENT VERBS

From a functional and cognitive linguistic paradigm, the effect of preverbs added is studied in a Manner of Motion Verb: volare. The corpus is established from all Ovid's poetic work from the study of semantic and grammatical difference of volare in simple or compound form, and the alteration of the telicity and transitivation of the clauses. Latin is a satellite-framed language and therefore the addition of preverbs will corroborate or not the hypotheses established about their effects.

Manner of motion verbs / Satellite-framed languages / Telicity / Transitivation / Preverbs 
Cuando despertó, el dinosaurio todavía estaba allí.

Augusto Monterroso, 1959 (A Eusebia T. R.)

\section{Objetivos}

El estudio se plantea en primer lugar establecer la diferencia semántica y gramatical de volare como Verbo de Manera de Moverse según se manifieste en forma simple o en forma compuesta con preverbios añadidos, en estos últimos alterando su comportamiento. En segundo lugar, se analiza el efecto de los preverbios añadidos -por lo tanto sólo en las formas compuestas- según cambie o no el carácter télico de la cláusula, corroborando el cumplimiento o no acerca de la hipótesis de los Verbos de Manera de Moverse, la cual establece que si estos son atélicos en forma simple, a partir de la añadidura de preverbios se convierten en télicos. También se estudia el efecto que el preverbio produce en la valencia verbal, es decir, si hace transitiva o no una cláusula formada por un verbo definido como regular intransitivo.

El corpus analizado es extraído de toda la obra completa de Ovidio a partir de la base de datos del programa computacional Diógenes (PHI), alcanzando un conjunto de 62 casos del verbo volare en el cual hay $39^{1}$ formas simples y 23 formas compuestas (se siguen las abreviaturas dadas por el Oxford Latin Dictionary, en adelante OLD). Los preverbios encontrados son: a- (Ars 2,19), ad- (Met. 6, 249; Met. 11, 384; Tr. 5, 10, 20), circum- (Met. 2, 719; Met. 14, 507; Tr. 2, 1, 171), con- (Fast. 6, 343), de- (Ars 3, 420), e- (Am. 3, 2, 78; Ars 3, 710; Met. 1, 264; Hal. 6), per- (Fast. 2, 252; Fast. 6, 527), pro- (Met. 12, 462; Fast. 6, 443), re- (Met. 7, 684; Met. 9, 742), sub- (Met. 11, 790; Met. 14, 507; Met. 14, 577), super- (Met. 4, 624).

Decidimos presentar ciertas traducciones canónicas de toda la obra poética de Ovidio (citadas en el apartado Bibliografía) guiándonos bajo el criterio de priorizar aquellas que estén traducidas en versos o en prosa con número de verso citado, con el fin de que tanto nosotros como quien quiera, tenga fácil y pronto acceso en la búsqueda del texto de los ejemplos citados.

\section{Breve introducción teórica}

La primera definición necesaria para el presente estudio se basa en las distinciones realizadas por TALMY $(1985,2003)$ entre las lenguas de marco por satélite (satelliteframed languages) y las lenguas de marco verbal (verb-framed languages).

Las lenguas de marco por satélite, como el latín, son aquellas que expresan en el verbo la Manera y el Movimiento, pero la Trayectoria la realizan mediante satélites que se corresponden en el latín con los preverbios. Por otro lado, las lenguas de marco verbal, como el español, expresan en el verbo la Trayectoria y el Movimiento mientras que la Manera debe ser formulada mediante un complemento adverbial. Vemos como ejemplo el siguiente caso: 
cum minime credas, ut avis, densissimus hostis

advolat, et praedam vix bene visus agit.

Cuando menos te lo esperas, numerosísimos

enemigos acuden volando como aves y, apenas sin ser

vistos, se llevan la presa (Tr. 5, 10, 19-20)

La forma compuesta advolat está constituida por el preverbio ad- que indica aproximación marcando dirección hacia un lugar, es un movimiento dirigido hacia un punto, indica el trayecto que va a realizar el verbo volat a partir del Movimiento -es acción- y Manera -implicada en volar-. El traductor (en la Bibliografía se citan las traducciones elegidas para cada obra) ha decidido el paso de una lengua de marco por satélite a una lengua de marco verbal a partir de la forma "acuden volando" es decir que el verbo conjugado "acuden" es el que indica la dirección hacia adelante -Trayectoria- y el Movimiento, mientras que la Manera la ha transformado en un complemento adverbial: "volando", que se corresponde con el significado del verbo latino.

Luego de esta distinción entre satellite-framed languages y las verb-framed languages es necesario establecer la diferencia entre los Verbos de Desplazamiento y los Verbos de Manera de Moverse, ambos Verbos de Movimientos.

Se ha discutido mucho sobre esta diferenciación (TESNIÈRE 1976, LAMIROY 1991, MORIMOTO 2001, CuARTERO OTAL 2006, entre otros) y hasta el día de hoy sigue habiendo enfrentamientos en las diferentes posturas. La diferencia entre los Verbos de Desplazamiento y los Verbos de Manera de Moverse, ambos Verbos de Movimiento, es bien definida y aclarada por TESNIÈRE (1976), postura retomada por LAMIROY (1991) y MORIMOTO (2001). Tesnière considera que ambos tipos verbales no se implican entre sí: puedo quedarme inmóvil en el avión al que subo viajando desde Argentina a España, donde hay desplazamiento pero no movimiento; y por el contrario, puedo hacer actividad física en una cinta caminadora a alta velocidad, donde sí hay movimiento pero no desplazamiento en el espacio (MоRIMOTO considera estos ejemplos extremistas, no aplicables a todas las actividades corrientes). El movimiento es intrínseco porque depende de condiciones somáticas del sujeto que efectúa dicho movimiento: el hombre corre porque tiene piernas, el ave vuela porque tiene alas, el pez nada porque tiene aletas, etc., por lo tanto este movimiento obedece no a la meta que persigue alcanzar sino más bien a sus posibilidades físicas y anatómicas. Los movimientos son diversos y complejos como los cuerpos que los realizan, es por eso que existen tantos verbos específicos que indican manera: correr, nadar, volar, saltar, etc. (TESNIĖRE 1976:538).

Por otro lado, TESNIÈRE (1976) nos aclara que el desplazamiento es extrínseco ya que implica un cambio de lugar, por lo tanto no se va a centrar en el sujeto sino más bien en el espacio en el que se realiza el trayecto. Al depender del nivel geométrico, los verbos de desplazamiento tienen valor matemático a partir de pares binarios: arriba/abajo, delante/detrás, derecha/izquierda que van a dar lugar a verbos también oponibles: subir/bajar, ir/venir, entrar/salir, etc.

Años más tarde, MORIMOTO (2001:46) revisa la clasificación hecha por TESNIÈRE (1976) y explica que los Verbos de Desplazamiento expresan dicho desplazamiento con 
una determinada orientación o dirección, mientras que los Verbos de Manera de Moverse se limitan a señalar la existencia de un desplazamiento sin concretar a nivel léxico qué tipo de trayectoria está implicada en dicho desplazamiento, la cual va a ser explicitada por complementos adverbiales. LAMIROY considera que

el que camina, nada, rema, se desplaza de un sitio a otro, pero el desplazamiento no se hace por referencia a un punto determinado por la posición del hablante y por la geometría del espacio. En cambio, el que sube o baja, entra o sale efectúa un desplazamiento orientado, polarizado por un punto determinado que no solo es pertinente sino que es constitutivo del sentido del verbo. (1991:65-66)

MORIMOTO explica que dentro de los Verbos de Movimiento, existen los Verbos de Manera de Moverse, los cuales define como aquellos que "expresan un evento que conlleva un desplazamiento del tema, dado el carácter indefinido o indeterminado de la trayectoria del movimiento denotado por ellos" (2001:46). A raíz de esto hace una subclasificación entre los Verbos de Manera de Moverse según su naturaleza sintáctica y semántica. Los Verbos de Manera de Moverse -VMMs- del tipo 'caminar, correr, saltar, volar' implican un desplazamiento y normalmente involucran alguna referencia espacial externa al objeto que se mueve y pueden aparecer con un Complemento de Trayectoria, por lo tanto decide etiquetarlos como VMM-Externos: voló (VMM-E) por los aires (CCL). Por el contrario, aquellos VMMs que denotan un movimiento estrictamente interno a un objeto decide llamarlos VMM-Internos, que son del tipo 'tambalearse' y no permiten Complemento de Trayectoria: *se tambaleó hacia el supermercado. Esto proviene de la distinción que realiza TALMY (1985 apud CARDINI 2008) entre dos tipos de movimientos fundamentalmente diferentes: translational y selfcontained, es decir aquellos que implican traslación en la localización, diferentes a los que implican el movimiento como sensación -mareo, tambalearse, patalear, entre otros.

Volare se configura como un Verbo de Manera de Moverse Externo ya que posee a nivel lexical el componente Manera de forma explícita y se define por el medio por el cual realiza el movimiento. Es de carácter externo ya que sí o sí implica desplazamiento en el espacio. Expresa la manera cómo lo realiza y se combina en su forma compuesta con distintos preverbios (satélites) latinos: ad-, sub-, circum-, ex-, entre otros. La traducción al español suele recoger la semántica de estos preverbios mediante complementos adverbiales, configurándose según la distinción inicial hecha por TALMY (1985, 2003) como verb-framed languages, lo cual seguiremos detallando más adelante.

Por último, interesa hablar de los preverbios y sus efectos. VAN LAER define el preverbio

comme un 'préfixe du verbe'. La notion de préverbe apparaît alors comme indissociable de celle de 'préverbation', qui est avant tout un procédé de création lexicale, consistant en l'association d'un élément préfixal à une base verbale pour former una nouvelle unité lexicale. (2010:7) 
El fenómeno de la lexicalización con preverbios es también explicado por TALMY: "lexicalization is involved where a particular meaning component is found to be in regular association with a particular morpheme" (1985:59). Dicho proceso lingüístico nos sirve para investigar si se está lexicalizando la ubicación y el desplazamiento de una entidad, y qué intención motivada aparecía en el plano cognitivo de los hablantes latinos cuando escuchaban o utilizaban un verbo lexicalizado con determinados preverbios.

Desde un método de investigación cognitivo, el análisis de la relación entre los verbos y los preverbios nos muestra que la elección de formas por parte del hablante no es algo aleatorio sino más bien que responde a ciertas "propiedades topológicas, geométricas o funcionales" (CIFUENTES Y LLOPIS 2000:320). Además, como señala RAMOS GUERREIRA (2010) citando a Bybee, para que un preverbio forme un nuevo ítem se ha de partir del hecho de que los significados que se funden en el léxico sean relevantes el uno para el otro, es decir, que el contenido semántico de uno de los elementos afecte o modifique el contenido semántico del otro (2010:560). Por lo tanto, la nueva unidad formada es motivada desde un nivel semántico y funcional.

En consecuencia, examinamos si volare aparece en latín solo (su forma simple) o con algún agregado locativo -preverbio, sintagma preposicional, expresión adverbialque indique dirección de Origen, Vía o Meta del movimiento. Es decir, nos proponemos diferenciar si el satélite nos indica desde dónde, por dónde o hacia dónde se realiza el movimiento de volar, según las 'windows of attention' (ventanas de atención que abre el hablante según qué desea que el lector/oyente focalice).

Según GARCíA HERNÁNDEZ (1980), las diversas acepciones que contrae un preverbio se clasifican en dos grupos, según la oposición sea entre dos modificados, o entre modificado y base léxica. Tenemos así la distinción entre funciones sémicas (significados propios y dados desde cada preverbio) y funciones clasemáticas (una misma función de significado es desempeñada por varios preverbios).

LORENZO LORENZO (1976:13 y ss.) en un estudio sobre el uso de los preverbios latinos en Jordanes, aclara la diferencia conceptual entre preverbio y preposición. Desde sus orígenes -Probo, Donato, Carisio, Diomedes- solo se apunta que la preposición es aquella partícula que se antepone necesariamente a cualquier parte de la oración. Se diferencia del adverbio (posteriormente preverbio) porque este último puede aparecer solo junto al verbo en posición anterior o posterior. Ya en el siglo XVII, ARNAULD Y LANCELOT (1676) ${ }^{2}$ establecen que las preposiciones marcan las relaciones que las cosas tienen entre sí, sean estas relaciones espaciales, temporales, etc. pero que no son fijas, sino que pueden marcar diferentes relaciones según la naturaleza de los términos unidos. No es la preposición la que modifica y condiciona a la palabra que contacta, sino al contrario: es esta palabra o el contexto en el que se produce el que fija una relación determinada a establecer por la preposición. Con respecto al adverbio, ambos autores aclaran que "la relación que existe entre el adverbio y el verbo es la misma que entre el adjetivo y el sustantivo" (LORENZO LORENZO 1976:16).

Se ha aclarado que este estudio analiza el efecto de los preverbios en el verbo volare como Verbo de Manera de Moverse. Una de las hipótesis que se baraja es la influencia que los preverbios tienen en relación a la telicidad, la cual se entiende como 
aquella característica incorporada en el contenido del verbo a partir de la idea de un límite inicial y/o final de la acción. Por el contrario, una cláusula se conforma como atélica cuando hay ausencia de telicidad, es decir cuando expresa un proceso o una actividad durativos, no delimitados desde el punto de vista de su aspecto léxico (BAÑOS BAÑOS 2013:768).

Se cree que la forma simple del Verbo de Manera de Moverse -en nuestro caso volare- es atélica y su forma compuesta, mediante la añadidura de preverbios, hace que sea télica. Pero resulta que no siempre es así, y no es en sí el carácter inherente del verbo el que va a marcar la presencia o ausencia de telicidad, sino más bien toda la construcción de la que el Verbo de Manera de Moverse forma parte.

\section{Presentación de volare}

Hemos considerado y definido el verbo volare como Verbo de Manera de Moverse Externo a partir de tres rasgos establecidos por MORIMOTO (2001:50): está presente el desplazamiento, la trayectoria es indeterminada y sí tiene manera de movimiento.

La primera definición que encontramos del verbo la brinda LEWIS E SHORT (s. v.) dando en primer lugar la acepción en sentido propio ('volar') y otra en sentido metafórico ('moverse rápidamente'). Por otro lado, el OLD (s. v.) lo define como verbo regular intransitivo. La primera definición la brinda como un verbo que tiene de Agente principal a aves o a criaturas mitológicas aladas. Luego, "To move through the air, empty space, etc" con todos seres inanimados, es decir, objetos de todo tipo. Y, en tercer lugar, define su uso metafórico, para aquello que se mueve a gran velocidad. Estos cuatro tipos de participantes (aves, criaturas mitológicas, seres inanimados y seres animados) aparecen en nuestro corpus. Podemos aunar las acepciones de los dos diccionarios diciendo que el verbo volare se utiliza tanto para el uso real del verbo como para un uso metafórico, recalcando la idea de velocidad cuando se trata de participantes humanos sin el instrumento que permite realizar la acción: alas.

Con respecto al aspecto lexical de volare, es decir, según su Aktionsart, lo definimos según los rasgos planteados por VENDLER $(1957)^{3}$ como un verbo que indica Actividad (activities) ya que inherentemente posee el rasgo de dinamismo y duración, pero carece de telicidad. Según la clasificación hecha a partir de rasgos semánticos por DIK (1989) volare se situaría dentro de las 'Acciones' ya que tiene control y dinamismo.

\section{Análisis de volare}

En el análisis presentado a continuación se estudia específicamente el evento de movimiento (definido por TALMY (1985:61) como "event that consists of one object (the 'Figure') moving or located with respect to another object (the reference-object or 'Ground'). It is analyzed as having four components: besides 'Figure' and 'Ground', there are 'Path' and 'Motion'”) dado a partir de volare con los siguientes elementos: quién (es decir qué Figura) realiza el desplazamiento (mediante el VMM volare) en el 
espacio exterior (Trayectoria) y a partir de qué elementos (Complementos Circunstanciales, Complementos Directos y Preverbios) cambia el carácter de una cláusula (sintácticamente: transitividad; semánticamente: telicidad y significado) y cómo se define dicho desplazamiento (ventanas de atención).

\title{
5. La Figura desde el plano sintáctico y semántico
}

Encontramos Figuras que realizan la acción (TALMY 1985:61), las cuales desde la definición dada arriba se conforman a partir de un evento de movimiento, el cual consiste en que un objeto (la Figura) se mueve o cambia de locación con respecto a otro objeto (el objeto-referente, o Fondo). Vemos el siguiente ejemplo:

\author{
aut ut apes saltusque suos et olentia nactae \\ pascua per flores et thyma summa volant, \\ o como las abejas, tras hallar \\ sus bosques y los prados olorosos, \\ vuelan por flores y romero alto, (Ars 1, v. 95-96)
}

Podemos analizar dicha situación de movimiento desglosando en los siguientes elementos descritos por TALMY: hay una Figura (apes) que se mueve (volant) con respecto a un Fondo (per flores et thyma summa). También se puede interpretar como un Fondo aún mayor el sintagma dependiente de la oración de participio: saltusque suos et olentia nactae pascua.

Los 62 casos del corpus de la obra completa de Ovidio presentan Figuras que desempeñan distintos roles semánticos y aparecen en el plano sintáctico expresadas como Sujeto.

El verbo volare generalmente exige como Figura un elemento explícito en la cláusula que se corresponda con el Sujeto de la acción de volar. Hay pocos ejemplos donde el Sujeto se encuentra elidido, pero siempre puede reponerse la Figura desde la morfología verbal o desde el elemento correferente a partir del recurso estilístico llamado 'elipsis'. El siguiente ejemplo elide la Figura pero se repone desde la morfología verbal: volabo: $1^{\circ}$ persona del singular:

denique quidquid ages, ante os oculosque volabo et querar, et nulla sede quietus eris.

Así que, hagas lo que hagas, volaré por delante de tu cara y tus ojos quejándome, y en ninguna parte encontrarás reposo (lb. 157-158)

Con respecto al nivel semántico, el verbo volare prefiere la utilización de Figuras más prototípicas en la agentividad, es decir con mayor control, volición e intención en la acción y mayor empatía con dichos rasgos. Pero si bien es una generalidad, no es la totalidad, ya que hay casos (menores, pero existentes) donde la Figura es miembro 
periférico en relación con el carácter de agentividad, ya que posee en menor grado el control, la intención y la voluntad al ser un elemento inanimado y no humano. En estos casos la Figura realiza la acción por el efecto de una causa explícita o que se le adjunta desde el cotexto, y es el momento cuando el autor se sirve del recurso estilístico de la 'personificación':

tu levior foliis, tum cum sine pondere suci

mobilibus ventis arida facta volant;

Pero tú eres más voluble que esas hojas secas que vuelan sin el peso de la savia, al capricho de los vientos (Ep. 5, 109-110)

En el ejemplo anterior se visualiza cómo la Figura foliis vuela a partir del efecto del viento, dado por la causa explícita mobilibus ventis.

\section{Trayectoria}

La Trayectoria (Path) es definida como el itinerario, es decir, el recorrido que realiza la Figura con respecto al Fondo. Es uno de los elementos centrales que TALMY (2003) considera dentro del evento de movimiento.

En todo evento de movimiento, el hablante enunciador del discurso crea 'windows of attention', es decir ventanas de atención, focalizando así la información y omitiendo otra, 'gapping'. De tal manera se puede decir "Cuando pasé por la Plaza Mayor, vi cámaras de filmación de Amenábar": situación de movimiento (pasé) que focaliza, es decir, dirige la atención hacia la ventana 'lugar por dónde' (por la Plaza Mayor) y omite el lugar de Origen (desde) y el lugar de Meta (hacia).

El trayecto puede significar: Origen (lugar del que se sale: de, desde, entre otros); Vía (lugar por el que se pasa: por, a través, entre otros); o Meta (lugar que se alcanza: hacia, hasta, entre otros).

En las formas simples de volare (39) cuantificamos 26 casos sin Trayectoria y tan solo 13 que la indican mediante Complementos Circunstanciales. Creemos que se debe a que el autor no quiere alterar la telicidad de la cláusula añadiéndole un punto de inicio o un punto final, y lo corrobora el hecho que de estos 13 casos hay 12 que presentan Trayectoria direccionados hacia la Vía, es decir que no alteran la telicidad:

tenues volat illa per auras

Vuela la corona a través de las auras ligeras (Met. 8, 179)

De estos 12 casos, tan solo 3 están en caso Ablativo ( 2 con preposición - Ars 2, 93-94; Tr. 3, 3, 61-64- y 1 sin preposición - Ars 3, 3-4) y 9 en caso Acusativo, con la preferencia de uso de las preposiciones per- e inter- (Ars 1, 95-96; Met. 8, 179; Met. 11, 650-652; Met. 8, 11-13; Met. 8, 200-206; Ars 2, 63-64; Ib. 157-158; Met. 12, $15-$ 19; 1 caso sin preposición: Met. 11, 749-750). 
Un caso es excepcional ya que indica Origen, por lo tanto altera la telicidad de la cláusula marcando un punto de inicio, pero justamente es el coincidente con el único ejemplo de volare en Pretérito Perfecto:

dedit ipse mihi modo signa futuri

Phoebus, et a laeva maesta volavit avis.

Así será: Febo mismo me dio presagios del evento, y un pájaro aciago voló desde la izquierda. (lb. 127-128)

El Complemento Circunstancial de Lugar que indica Trayectoria de Origen es a laeva. La preposición 'a' + Ablativo posee las Funciones Semánticas de Origen, Tiempo, Duración y Causa-Fin (BAÑos 2009:315). En este contexto, al estar funcionando como Complemento Preposicional de un Verbo de Manera de Moverse, optamos por elegir el significado de Origen, es decir, el lugar desde dónde realiza el movimiento la Figura (avis). Esta preposición junto a un nombre en caso Ablativo significa 'alejamiento de las proximidades, sin contacto con el referente espacial' (BAÑOs BAÑos 2009:326).

Por lo tanto, vemos en el ejemplo que venimos explicando que la telicidad está marcada por el tiempo verbal (Pretérito Perfecto: volavit) y por el Complemento Circunstancial que marca Origen (a laeva).

Por último, tenemos un único caso formulado con volare en forma simple que llama la atención porque es inusual su construcción de la manera que presenta aquí:

Hos aliquis senior iunctim freta lata volantes

spectat et ad finem servatos laudat amores:

Mientras ellos sobrevuelan juntos el ancho mar, un anciano

los contempla y ensalza aquel amor hasta el final. (Met. 11, 749-750)

Encontramos este caso donde el Participio Presente (volantes) tiene como Complemento un Objeto Directo (freta lata) en Neutro Acusativo Plural, donde freta es el Núcleo y lata el Modificador. Llama la atención que este verbo intransitivo por naturaleza, se transitive solo con el efecto de indicar mediante este Objeto Directo la afectación en el espacio (GIVÓn 2001:131), el cual se conforma como Lugar por Dónde o en el Lugar que están volando las Figuras. En palabras de Givón (2001:131) "By metaphoric extension, the locative object becomes patient-like, appearing to be more affected by the event: She swam the channel (>She swam across the channel)".

Si bien vemos que la transitivación en este único caso de forma simple no afecta a la telicidad del verbo, el Objeto Directo se construye como un espacio sin principio ni fin. Es decir, el mero hecho de añadir un Objeto no implica la telicidad de la predicación, sino que es necesario que sea un Objeto de referente delimitado: I watched a fish (Atelic-Activity) / I watched a film (Telic-Accomplishment) (LYNNE MURPHY 2010:212). 
En las formas compuestas de volare tenemos 23 casos conformados por preverbios. Se resumen los rasgos en el cuadro a continuación:

\begin{tabular}{|c|c|c|c|c|c|c|}
\hline & $\begin{array}{l}\text { Origen: Aleja- } \\
\text { miento (de, desde) }\end{array}$ & $\begin{array}{l}\text { Meta: Aproxima- } \\
\text { ción (hacia, a) }\end{array}$ & $\begin{array}{l}\text { Vía: } \\
\text { A través } \\
\text { (por) }\end{array}$ & $\begin{array}{l}\text { Origen y Meta: } \\
\text { Alejamiento y } \\
\text { Aproximación }\end{array}$ & Telicidad & Transitivación \\
\hline$A b-(1)$ & + & - & - & - & + & - \\
\hline$A d-(3)$ & - & + & - & - & + & - \\
\hline Circum- (3) & - & - & + (acecho) & - & + & + \\
\hline Con- (1) & - & - & - & - & + (cláusula) & - \\
\hline$D e-(1)$ & + & + & - & + & + & - \\
\hline$E x-(4)$ & + & + & - & + & + & - \\
\hline Per- (2) & + & + & + & + & + & $+(1) /-(1)$ \\
\hline Pro- (2) & + & $+(1)$ & - & $+(1)$ & + & - \\
\hline $\operatorname{Re}-(2)$ & + & + & - & + & + & - \\
\hline Sub- (3) & + & $+(1)$ & - & $+(1)$ & + & - \\
\hline Super- (1) & - & - & + & - & - & + \\
\hline
\end{tabular}

Explicaremos a continuación aquellos casos que llaman más la atención con respecto a la hipótesis inicial del efecto de los preverbios añadidos a un Verbo de Manera de Moverse.

Circum- es un preverbio que significa "alrededor de" y por lo tanto indica Vía. Encontramos que, sin embargo, altera la telicidad de la cláusula ya que los tres casos donde aparece (Met. 2, 719; Met. 14, 507; Tr. 2, 1, 171) tienen significado de acecho, por lo tanto, de meta, que alcanzar sea la ansiada presa, los remos o la gloria. También en los tres casos produce el efecto de alterar la transitivación de la claúsula: este elemento de acecho es un Acusativo, es decir Complemento Directo, que permite la transitivación. Por lo tanto no es el preverbio por sí solo el que altera o no la telicidad, sino la cláusula completa.

Con- es un preverbio que como se visualiza en el cuadro no indica Trayectoria, ya que esta forma proviene del antiguo cum- y que por un proceso de evolución fonética y sintáctica en Ovidio (y en su época) se presenta con la forma con-. Este preverbio en realidad indica la realización conjunta de una acción por parte de varios Agentes o por un Agente colectivo, como es nuestro caso: omnis turba (Fast. 6, 343-344). Sin embargo, consideramos que este preverbio altera la telicidad de la cláusula porque la entendemos en su totalidad. A partir del verbo de la cláusula anterior (surgit dea) se entiende que el movimiento que realiza todo el grupo es hacia una meta: lugar donde la diosa se ha levantado.

El preverbio per- presenta dos casos en Ovidio pero solo analizaremos ahora el que transitiva la cláusula (Fast. 2, 251-252). En realidad, si buscamos en el diccionario la forma verbal pervolat encontramos que es un verbo transitivo a partir del preverbio. Es decir que es el otro caso el que debería llamar la atención (Fast. 6, 527). Pero ya que estudiamos la transitivación nos centraremos en el ejemplo de Fast. 2, 251-252, el cual presenta un Complemento Directo -aerium iter- para especificar el lugar que 
atraviesa la Figura mediante el significado indicado por el preverbio, y hace la cláusula de manera télica.

Por último, el preverbio super- es el más importante en nuestro estudio ya que rompe con esa hipótesis inicial acerca de que el Verbo de Manera de Moverse volare es en su forma simple atélico y en su forma compuesta télico. Presentamos el único caso que utiliza el preverbio super-:

ex alto seductas aethere longe

despectat terras totumque supervolat orbem.

desde lo alto contempla a lo lejos las tierras separadas de él

por el cielo y va sobrevolando por el mundo entero (Met. 4, 623-624)

Este preverbio sí transitiva la cláusula pero no la convierte en télica, mantiene la ausencia del rasgo del aspecto léxico de la telicidad. Marca la idea contraria a sub- ya que tiene el valor local de 'sobre' o 'encima'. También puede aplicarse al valor temporal y nocional. Frente al matiz de sub- de restricción o disminución en la intensidad, superpuede añadir la idea de intensidad y superioridad.

El OLD (s. v.) define este compuesto con el único valor de 'volar sobre'. Por otro lado, LEWIS \& SHORT (s. v.) también lo definen como 'volar sobre' pero aclaran que este verbo es creación de los poetas augusteos y aparece luego, en época postaugustea, en poesía y prosa. Esto nos justifica que aparezca un solo caso, ya que no está aún totalmente establecida esta forma compuesta.

Esta cláusula además de ser transitiva presenta un Complemento Circunstancial de Lugar que coincide con ese Complemento Directo que rige dicho preverbio: totum orbem. Es decir que el sentido que se utiliza en este caso es el del valor local 'encima de'.

GARCíA HERNÁNDEZ (1980:209) también aclara que es un caso postclásico y tardío. En Ovidio nos interesa el ámbito que indica espacio significando 'por encima de', traducido como 'sobrevolando por el mundo entero' (RAMíREZ DE VERGER y NAVARRO ANTOLÍN). Esta función indica orientación vertical y nivel superior por oposición a sub-.

LORENZO LORENZO (1976:271) lo define como la idea contraria de sub-, con valor de 'sobre' y 'encima' que puede tener tres sentidos: espacial, temporal y nocional. El sentido espacial lo define con el significado de 'encima' y llama la atención sobre el hecho que los poetas del siglo I lo emplean en forma personal, a diferencia de por ejemplo JORDANES que es quien él estudia. En concordancia con GARCíA HERNÁNDEZ, el uso de Ovidio recoge el significado local.

La traducción respeta este significado de volar por encima de algo que se corresponde con el Complemento Directo que aparece en su lengua original, lo que lo convierte a este verbo en transitivo. El Complemento Directo está indicando Fondo y Vía.

Lo que resalta es el hecho que no altere la telicidad de la cláusula, como venimos diciendo. Creemos que esto se debe a que en un análisis de frecuencia de uso de los distintos preverbios (Perseus, tabla siguiente), super- + volare presenta tan solo 14 
usos distribuidos en 10 autores. Al ser una forma que está naciendo, no está establecida su manera de uso, no se tiene una conciencia lingüística de manejo total por parte de los hablantes como sí sucede con los otros preverbios.

\begin{tabular}{l|l|l}
\hline Preverbio & \multicolumn{1}{l}{ Frecuencia de uso } & Autores \\
\hline$A b-$ & 50 & Vulgata, Cicero, Ammianus Marcellinus, ... + \\
\hline Ad- & 223 & G. Plinius Secundus, Cicero, Valerius Flaccus, ... + \\
\hline Circum- & 45 & Statius P. Papinius, Silius Italicus, Vergilius, ... + \\
\hline Con- & 49 & Amianus Marcellinus, Titus Livius, ... + \\
\hline De- & 57 & G. Plinius Secundus, ... + \\
\hline Ex- & 172 & G. Plinius Secundus, Ammianus Marcellinus, Silius Italicus, .... + \\
\hline Per- & 78 & Ammianus Marcellinus, Vitruvius Pollio, ... + \\
\hline Pro- & 49 & $\begin{array}{l}\text { Titus Livius 20, Chaula Tommaso Chiaramonte 11, no más de } 5 \text { autores } \\
18 \text { usos. }\end{array}$ \\
\hline Re- & 33 & Chaula Tommaso 5, Columella 4, poco más de 5 autores 24 usos. \\
\hline Sub- & 11 & $\begin{array}{l}7 \text { autores: G. Plinius Secundus, Ovidius, Cicero, Apuleius, Columella, } \\
\text { Prudentius, Landino. }\end{array}$ \\
\hline Super- & 14 & $\begin{array}{l}10 \text { autores: G. Plinius Secundus, Maurus Servius, Aulus Gellius, Valerius } \\
\text { Maximus, Ovidius, Statius, Vergilius, Augustine, Phaedrus, Ausonius. }\end{array}$ \\
\hline
\end{tabular}

\section{Conclusiones}

Concluimos estableciendo que el análisis lingüístico detallado permite entender mejor el texto poético porque pone de relieve la plasticidad de la lengua en manos de un autor como Ovidio, realizando un estudio lingüístico que podrá servir en oportunidades futuras para aplicar a una mejor comprensión de la obra del autor en un nivel literario.

En el caso que una obra poética esté escrita en un tipo de lengua y deba ser traducida hacia otra lengua de diferente tipo, vislumbramos la dificultad que se les presenta a los traductores cuando tienen que verter al español la información que el poeta concentra en una forma verbal latina, la conexión entre forma y contenido, siempre perceptible en cualquier texto literario pero más aún en la poesía.

Comprobamos también que las reglas gramaticales no pueden estudiarse fuera de contexto ya que son el texto mismo y la cláusula completa los que corroboran el cumplimiento o no de hipótesis iniciales, postulando de esta manera al nivel pragmatico como el esencial en la lengua, sin dejar de lado los otros niveles.

El objetivo principal de nuestro trabajo es demostrar los efectos que ocasionan los preverbios sobre todo en cuanto al rasgo de telicidad. Se cree por regla general que algunos Verbos de Manera de Moverse en su forma simple (en nuestro caso volare) tienen carácter atélico y los compuestos con preverbios añadidos, cambian a télicos. Comprobamos que prototípicamente esto sucede, pero no es una exigencia que olvide la intención del yo lírico, ya que super- y cum- no afectan al verbo desde la alteración de este rasgo (cum- sí lo hace pero solo es inferible por cotexto).

La estética literaria de un autor, en este caso de Ovidio, puede ser abordada desde un nivel lingüístico entendiendo al poeta como un ser con intención comunicativa que 
a partir de sus elecciones define distintos recursos literarios: utiliza la metáfora en el uso no real del verbo, la personificación con Figuras inanimadas pero que son Agentes de la acción, la elipsis cuando elide el sujeto del verbo, las imágenes sensoriales a partir de Complementos Circunstanciales, etcétera.

Ovidio es un poeta consciente de la forma que elige, cómo la construye, cuál es la intención que quiere transmitir, y nosotros hemos intentado demostrar todos estos aspectos y hacer un aporte lingüístico funcional a una obra literaria.

\section{Bibliografía}

BaÑos BaÑos, J. M. (2009) "XI. Preposiciones" en Sintaxis del latín clásico. José Miguel BAÑOS BAÑOS (coord.) (pp. 299-347). Madrid: Ed. Liceus E-Excellence.

BAÑos BAÑos, J. M. (2013) "Dos tipos de intransitividad en latín: sintaxis y semántica”, en Ianua Classicorum. Temas y formas del Mundo Clásico. Actas XIII Congreso Español de Estudios Clásicos, Logroño, 2011. Vol. I. (pp. 759-790).

CARDINI, F. E. (2008) "Manner of motion saliency: An inquiry into Italian”, en Cognitive Linguistics. 19.4, 533-569

Cifuentes HonrubiA, J. L. y Llopis GangA, J. (2000) "Sobre la semántica de los verbos de desplazamiento y su tipología", en Cien años de investigación semántica: de Michel Bréal a la actualidad. Actas del Congreso Internacional de Semántica. Universidad de La Laguna, Octubre, 1997. Vol. I. (pp. 319-332). Madrid: Ediciones clásicas.

CUARTERO OTAL, J. (2006) "¿Cuántas clases de verbos de desplazamientos se distinguen en español?", en Revista del Instituto de Lenguas y Culturas Españolas, Universidad de Navarra (RILCE). 22.1, 13-36.

DIK, S. C. (1989) The theory of functional grammar. Dordrecht, Holland; Providence, RI, U.S.A.: Foris Publications.

DiogenES WeB. [en línea]. https://d.iogen.es/web?ver=1.002Euser=stud [consulta: 18 de marzo de 2020].

FERNÁNDEZ CORTE, J. C. y CANTÓ LloRCA, J. (2008) Ovidio. Metamorfosis, Libro I-IV.Madrid: Gredos.

GARCíA HeRnándeZ, B. (1980) Semántica estructural y lexemática del verbo. Reus: Ediciones Avesta.

GIVÓN, T. (2001) "Simple verbal clauses and argument structure", en Syntax. Vol. I. (pp. 105 171). Amsterdam / Philadelphia: John Benjamins Publishing Company.

GLARE, P. G. W. (ed.) OLD - Oxford Latin Dictionary. $2^{\circ}$ ed. (2012). London: Oxford University Press.

GonZÁlez IgLeSIAS, J. A. (1993) Ovidio. Amores; Arte de amar. Madrid: Cátedra.

GONZÁlez VÁzQUEZ, J. (1992) Ovidio. Tristes; Pónticas. Madrid: Gredos.

LAMIROY, B. (1991) Léxico y gramática del español: Estructuras verbales de espacio y de tiempo. Barcelona: Antrophos. 
LEWIS, T. C. \& SHORT, C. (1891) Latin Dictionary. Oxford: Clarendon Press. [pdf] Disponible en:

https://archive.org/stream/LewisAndShortANewLatinDictionary/lewisandshort\#page/n0/m ode/2up [20 de Junio de 2018]

LóPEZ SOTO, V. (1979) Ovidio. Metamorfosis. Barcelona: Bruguera.

LORENZO LORENZO, J. (1976) El valor de los preverbios en Jordanes. Salamanca: Universidad de Salamanca.

LyNNE MuRPHY, M. (2010) Lexical Meaning. Cambridge: University Press.

MORIMOTO, Y. (2001) Los verbos de movimiento. Madrid: Visor Libros.

Pérez VeGA, A. (1994) Ovidio. Cartas de las heroínas; Ibis. Madrid: Gredos

Ramírez de Verger, A. y NaVArRo Antolín, F. (1998). Ovidio. Metamorfosis. Madrid: Alianza.

RAMOS GueRREIRA, A. (2010) "Preverbios en verbos de expresión latinos: apuntes sobre lexicalización e historia de las palabras", en Dic mihi, musa, virum: homenaje al profesor Antonio López Eire. Francisco CoRTÉs GABAUDAN, Julián Víctor MÉNDEZ DosunA (eds.) (pp. 559-568). Salamanca: Universidad de Salamanca.

SEguRa Ramos, B. (1988) Ovidio. Fastos. Madrid: Gredos.

TALMY, L. (1985) "Lexicalization patterns: semantic structure in lexical forms", en Language, tipology and syntactic description - III. Ed. Timothy SHOPEN (pp. 57-149). Cambridge: Cambridge University Press.

TALMY, L. (2003) Toward a cognitive semantics. Volume I: Concept structuring systems y Volume II: Typology and process in concept structuring. Cambridge, Massachusetts: MIT Press.

TESNIÈRE, L. (1976) Elementos de sintaxis estructural. Trad. esp. Esther Diamante (1994). Madrid: Gredos.

VAN LAER, S. (2010) La préverbation en latin: étude des préverbes ad-, in-, ob-et per- dans la poésie républicaine et augustéenne. Volume 325. Collection Latomus. Bruxelles: Éditions Latomus.

VAN VAliN, R. D. JR. Y LAPOLLA, R. J. (1997) Syntax: structure, meaning and function. Cambridge: Cambridge University Press.

\section{Notas}

${ }^{1}$ Am. 1, 6, 13; Ep. 5, 110; Ep. 6, 66; Ars 1, 96; Ars 2, 63; Ars 2, 69; Ars 2, 76; Ars 2, 94; Ars 3, 4; Met. 2, 709; Met. 2, 728; Met. 4, 415; Met. 5, 158; Met. 6, 708; Met. 7, 400; Met. 8, 13; Met. 8, 179; Met. 8, 180; Met. 8, 206; Met. 8, 208; Met. 8, 213; Met. 8, 353; Met. 8, 357; Met. 10, 587; Met. 11, 650; Met. 11, 731; Met. 11, 734; Met. 11, 749; Met. 12, 16; Met. 12, 243; Met. 12, 568; Met. 13, 604; Met. 15, 848; Fast. 6, 135; Tr. 3, 3, 61; Tr. 3, 4, 23; Tr. 3, 10, 55; Ib. 128; Ib. 157.

\footnotetext{
${ }^{2}$ Apud LoRENZO LORENZO (1976:15-16).

${ }^{3}$ Apud Van Valin $\&$ LaPolla $(1997: 91)$.
} 